\title{
Characterization of Microstructural Refinement and Hardness Profile Resulting from Friction Stir Processing of 6061-T6 Aluminum Alloy Extrusions
}

\author{
Nelson Netto, Murat Tiryakioğlu * and Paul D. Eason \\ School of Engineering, University of North Florida, Jacksonville, FL 32224, USA; netto993@hotmail.com (N.N.); \\ paul.eason@unf.edu (P.D.E.) \\ * Correspondence: m.tiryakioglu@unf.edu; Tel.: +1-904-620-1390
}

Received: 13 June 2018; Accepted: 15 July 2018; Published: 19 July 2018

check for updates

\begin{abstract}
In this study, the change in microstructure and microhardness adjacent to the tool during the friction stir processing (FSP) of 6061-T6 extrusions was investigated. Results showed that the as-received extrusions contained Fe-rich constituent particles with two distinct size distributions: coarse particles in bands and finer particles in the matrix. After FSP, Fe-containing particles exhibited single-size distribution and the coarse particles appeared to be completely eliminated through refinement. Microhardness tests showed the presence of four distinct zones and that hardness increased progressively from the dynamically recrystallized closest to the tool, outward through two distinct zones to the base material. The similarities and differences between the results of this study and others in the literature are discussed in detail.
\end{abstract}

Keywords: Vickers microhardness; Fe-containing constituents; lognormal distribution

\section{Introduction}

Friction stir processing (FSP) is a technique, derived from friction stir welding [1,2], where a rotating tool consisting of a pin and shoulder is plunged into the material until the shoulder contacts the outside surface of the workpiece. Subsequently, the tool is forced along the plane of the surface of the material, while the shoulder remains in contact with the workpiece. The pin forces the material to undergo intense plastic deformation, resulting in a refined, homogenized, and recrystallized microstructure [1-4]. This microstructural modification has been stated as the reason for improvement in mechanical properties, such as tensile properties and fatigue life [5-10]. Process parameters, such as rotational and transverse speed, and choice of tool geometry are critical to the material flow and to the resulting microstructural modification. Recent studies [11,12] have developed modeling methods to optimize process parameters. It should be noted that, for each material and application, there is a unique set of optimum process parameters [13]. For the current study, the authors previously developed the process parameters and the methodology in that approach which can be found in a separate publication [14]. The intent of this study was to document the phenomena of microstructural modifications, which have been largely underexplored in the literature.

Among the microstructural features that are modified during FSP are Fe-containing constituent phases [15] that form in aluminum alloys during solidification [16], and are known to reduce tensile properties [17]. It was demonstrated that the size distribution of Fe-containing constituents can be taken as the flaw size distribution in wrought aluminum alloys. DeBartolo et al. showed that the reduction of the sizes of Fe-containing constituent particles from FSP leads to smaller effective size of defects and consequently to higher tensile strength and elongation, as well as longer fatigue life [18].

Microstructural effects from FSP occur as a result of the deformation that occurs due to the stirring action of the submerged tool. The effect of the stirring action during FSP changes drastically 
with distance from the tool, leading to distinct zones in the microstructure from both mechanical deformation and heat dissipation zones. Woo et al. [19] characterized the microstructure of 6061-T6 alloy plates after FSP. They reported four zones: (i) the dynamically recrystallized zone (DXZ), which is the fully processed zone caused by the stirring action; (ii) the thermomechanically affected zone (TMAZ), which is generated due to the deformation and heat from the plastic deformation in DXZ; (iii) the heat affected zone (HAZ); and (iv) the base metal (BM), which is not affected by the heat. These different zones exhibit different hardness profiles. Figure 1 describes the hardness profile for each zone after different process times (after 168 hrs. and 5760 hrs. of FSP). The DXZ shows a lower hardness profile than the BM, likely due to the coarsening and/or dissolution of strengthening precipitates in the Al matrix. Minimum Vickers hardness (Hv), in Figure 1, is at the TMAZ-HAZ transition on both sides of the tool for all cases. Similar results were reported for the FSW of 6061-T6 [20]. Note in Figure 1 that the change in HV from DXZ to BM is approximately 25-30 in both cases.

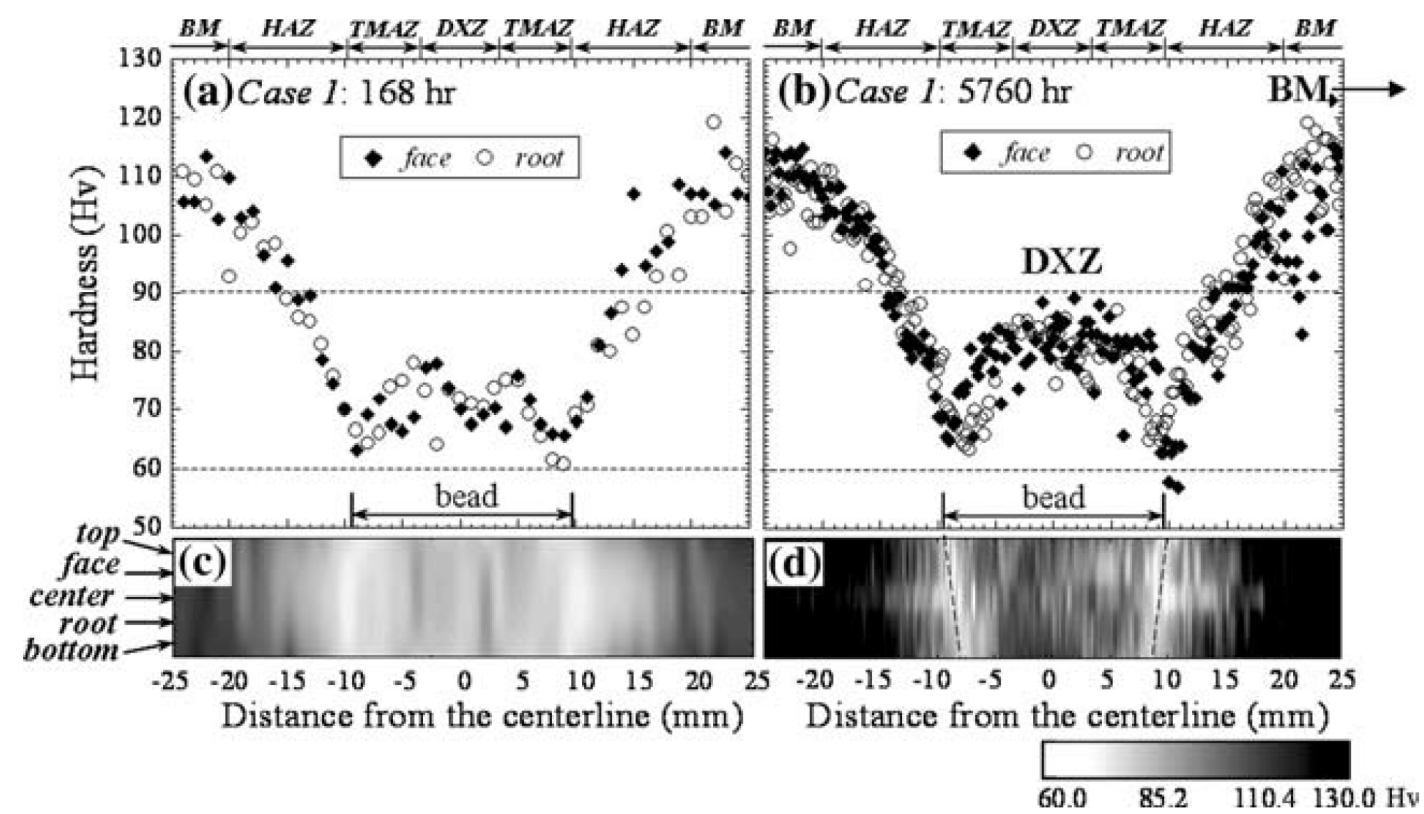

Figure 1. Hardness profiles measured along the face and root in Case 1: (a) $168 \mathrm{~h}$ and (b) $5760 \mathrm{~h}$ after friction stir processing (FSP); (c) and (d) present hardness maps, with a scale shown in the bottom right of the image [15] (US Government Work, no copyright).

\section{Materials and Methods}

Extruded bars of a 6061-T6 aluminum alloy with the dimensions $330 \times 25.4 \mathrm{~mm}$ were used in this study. FSP was conducted on a Bridgeport vertical milling machine, with the FSP tool tilted $3^{\circ}$ opposite to the processing direction. The tool rotation rate and transverse speed were kept constant at $700 \mathrm{rpm}$ in a clockwise direction and $50 \mathrm{~mm} / \mathrm{min}$, respectively. The FSP tool was made of H13 tool steel with a shoulder diameter of $18 \mathrm{~mm}$. The cylindrical pin had a diameter of $5.9 \mathrm{~mm}$, a length of $5 \mathrm{~mm}$, and M6-threads. After FSP, samples were sectioned by low-speed saw, mounted in epoxy, and prepared by standard metallographic polishing methods. To evaluate the hardness profile for each FSP zone in the 6061-T6 extrusion, microhardness tests were carried out on a Shimadzu HMV G21 automated Vickers microhardness tester with load of $98.07 \mathrm{mN}$ and dwell time of $15 \mathrm{~s}$. A Tescan Mira 3 Field Emission Scanning Electron Microscope (FE-SEM) equipped with an Oxford Instruments X-Max 50 energy dispersive spectrometer (Abingdon, Oxford, UK) was used to evaluate microstructure on unetched specimens. 


\section{Results and Discussion}

The microstructure of the 6061 extrusion (base material) used in this study is shown in Figure 2a, which shows bands of constituent particles along the extrusion direction. The X-ray map for Fe is presented in Figure 2b, which shows that large as well as finer particles contain Fe. Moreover, these particles were also found to contain $\mathrm{Si}$, which are typical of constituent particles in aluminum alloys [16]. Both large and smaller constituent particles containing Fe and Si are visible in Figure 3. The finer particles within the bands probably fractured during the extrusion process.

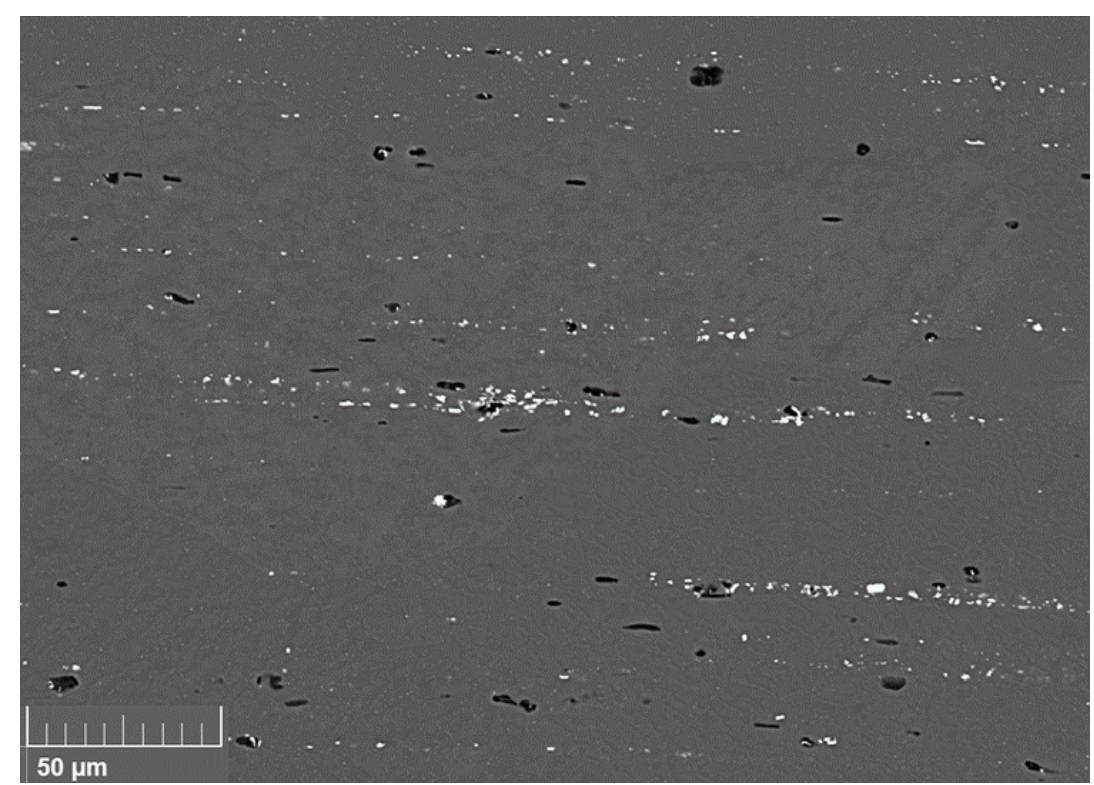

(a)

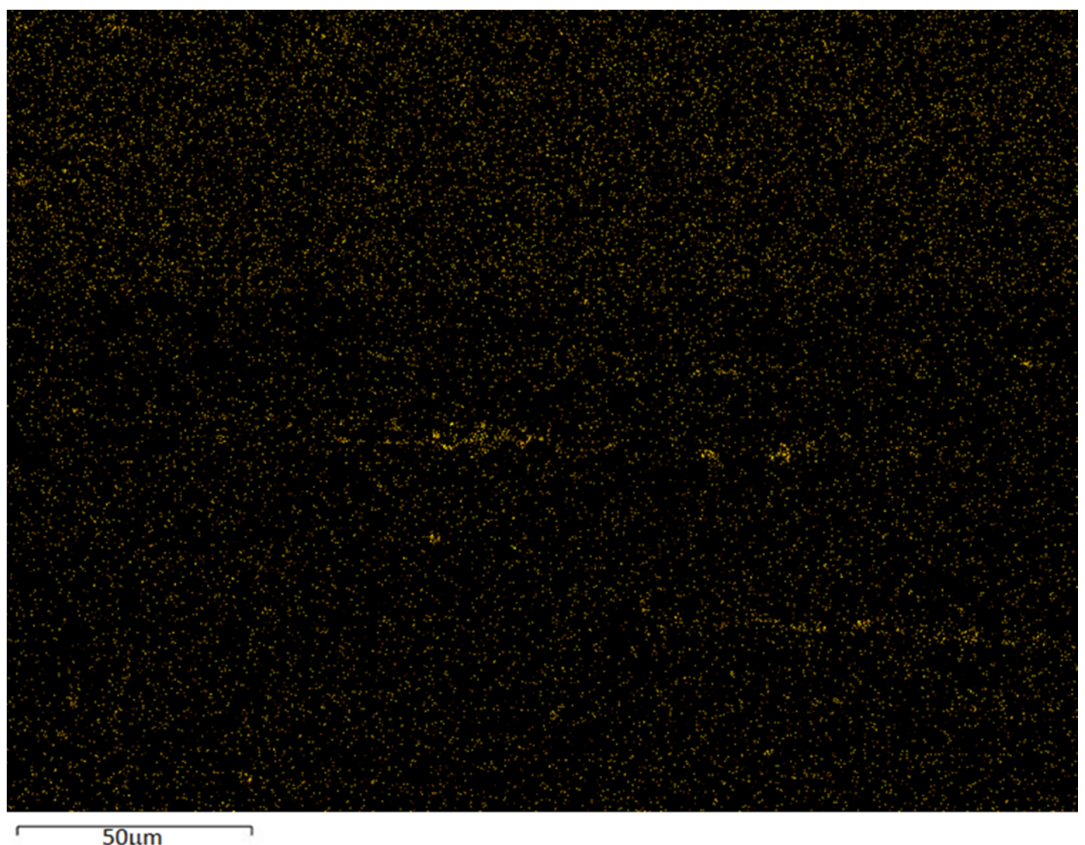

(b)

Figure 2. (a) SEM micrograph, taken in BackScattered Electron (BSE) mode, of the microstructure of the aluminum matrix and (b) X-ray map for Fe of the same region, which indicates that bright particles in the micrograph contain iron. 


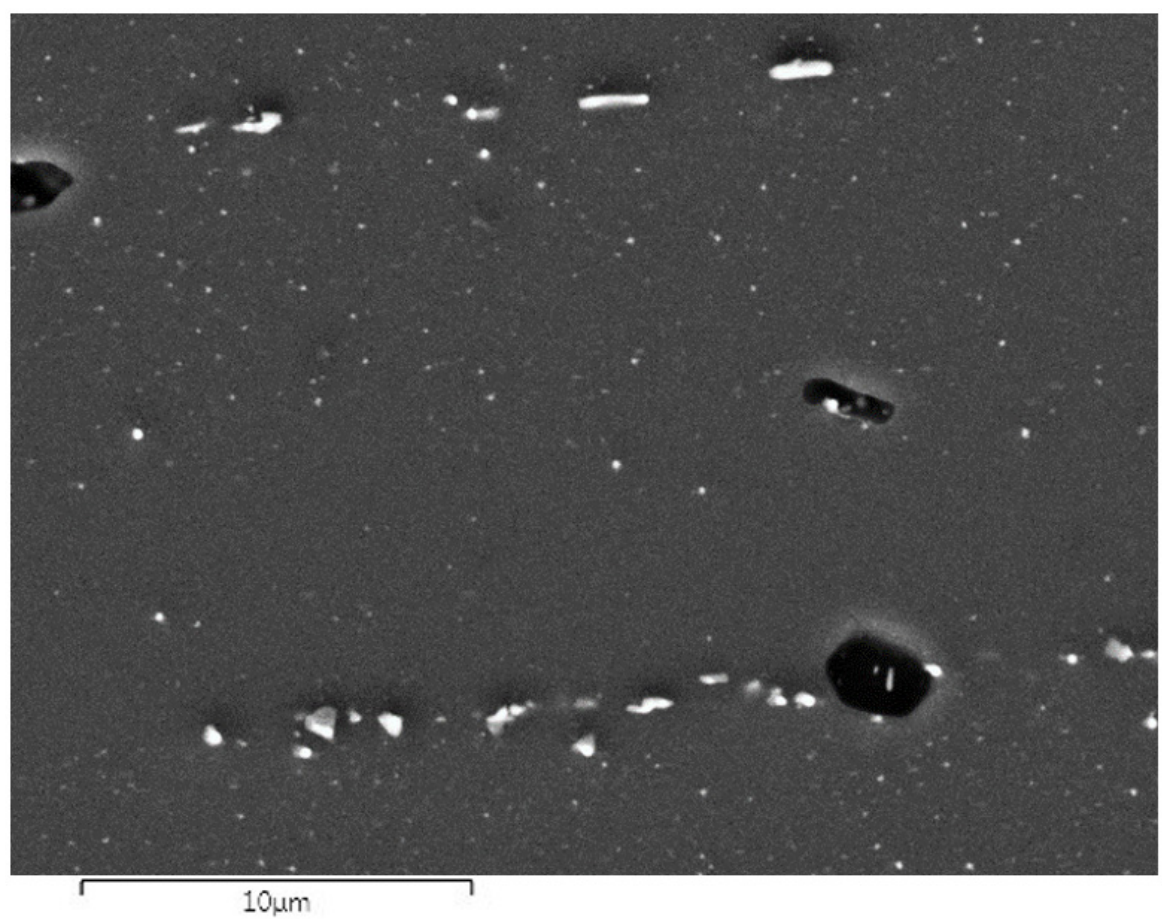

Figure 3. SEM micrograph taken in BSE Mode at higher magnification than Figure 2, showing the microstructure of 6061-T6, showing the Fe-rich constituent sizes and their distribution.

Moreover, the boundary between DXZ and TMAZ is visible at approximately $300 \mu \mathrm{m}$ to the left from the lower tip of the tool (Figure 4). To the right of this boundary, i.e., in DXZ, the spacing of particles seems to be random. In contrast, the particles are in bands as shown in Figure 2 to the left of the boundary.

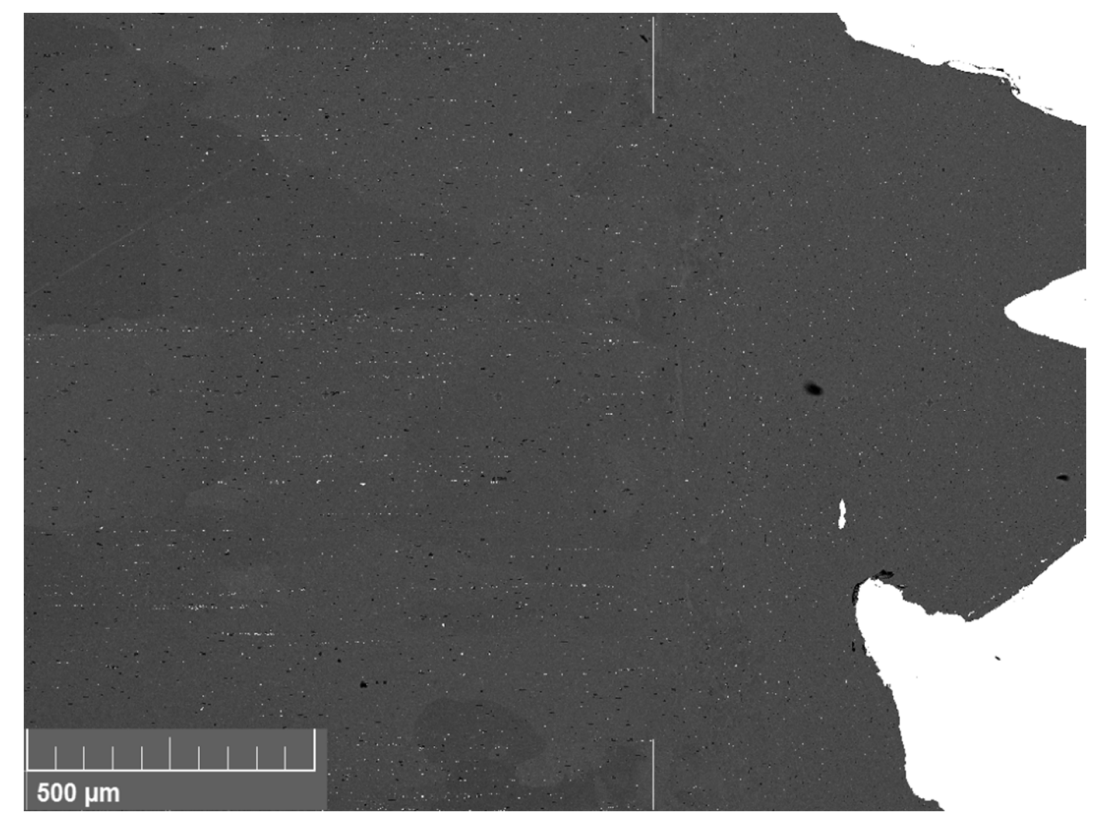

Figure 4. SEM micrograph taken in BSE mode with vertical lines added to show the boundary of the stir zone adjacent to the tool. Note: The bright particle observed above and to the left of the thread tip was determined to be a fractured piece of the tool. 


\subsection{Characterization of the Effect of FSP on Microstructure}

To further evaluate the effect of FSP in microstructural refinement, digital image processing was conducted with Image Version 1.52e free downloadable software (National Institutes of Health, Bethesda, MD, USA) to determine the sizes of the Fe-containing constituent particles. Equivalent diameter of Fe-bearing particles, $\mathrm{d}_{\mathrm{Fe}}$, was calculated as

$$
\mathrm{d}_{\mathrm{Fe}}=\sqrt{\frac{4 \mathrm{~A}}{\pi}}
$$

Subsequently, the Fe particle size distribution for every condition was determined by hypothesizing that size follows the lognormal distribution, which is consistent with results reported in the literature [15] for $\beta$-phase $\left(\mathrm{Al}_{3} \mathrm{FeSi}\right)$ platelets in aluminum alloys. The density function, $\mathrm{f}$, of the three-parameter lognormal distribution is written as:

$$
f(x)=\frac{1}{(x-\tau) \sigma \sqrt{2 \pi}} \exp \left[\frac{-(\ln (x-\tau)-\mu)^{2}}{2 \sigma^{2}}\right]
$$

where $\tau$ is the threshold value below which probability of $x$ is zero, $\mu$ is the location parameter, and $\sigma$ is the scale parameter.

Consistent with the observations stated previously about Figure 2, it was noticed that in the BM region there were two Fe-containing particle size distributions: coarse particles in bands, and finer particles within the matrix. The probability density function (f) for the mixture of two distributions is written as [21]:

$$
\mathrm{f}=\mathrm{f}_{1} \cdot \mathrm{p}+\mathrm{f}_{2} \cdot(1-\mathrm{p})
$$

where $\mathrm{p}$ is the fraction of the distribution of the lower distribution and subscript 1 and 2 refer to the lower and upper distributions, respectively. The estimated parameters of lognormal distributions are given in Table 1.

Table 1. Estimated parameters of the lognormal distributions and the fraction of each distribution in the mixture.

\begin{tabular}{cccccc}
\hline FSP Zone & $\boldsymbol{\tau}(\boldsymbol{\mu} \mathbf{m})$ & $\boldsymbol{\mu}$ & $\boldsymbol{\sigma}$ & $\mathbf{p}$ & $\mathbf{d}_{\mathrm{Fe}}(\boldsymbol{\mu} \mathbf{m})$ \\
\hline BM (fine) & 0.333 & -2.247 & 0.804 & & 0.858 \\
BM (coarse) & 0.695 & -0.291 & 0.772 & & 1.70 \\
\hline DXZ & 0.345 & -2.034 & 1.133 & & 0.59 \\
\hline
\end{tabular}

After FSP, the processed microstructure in DXZ is composed mostly of small particles, as shown in Figure 5, which is a further magnification of the microstructure in Figure 4. Hence, there is strong evidence of a refined and homogeneous microstructure after FSP. The upper distribution for large particles is completely eliminated, and all Fe-containing particles are similar in size.

The probability plots of the lognormal distributions for the sizes of Fe-containing particles are shown in Figure 6. Note that the distribution for coarse particles is completely eliminated. Hence, coarse particles are broken to the size of fine particles in the extruded microstructure. This result is in agreement with the results of a previous study [15].

The mean of a three-parameter lognormal distribution is found by:

$$
\mathrm{d}_{\mathrm{eq}}=\tau+\mathrm{e}^{\mu+\frac{\sigma^{2}}{2}}
$$


The particles sizes calculated from estimated distribution parameters are also provided in Table 1. The average particle diameter after DXZ after FSP is $0.59 \mu \mathrm{m}$, which is comparable to the average fine particle diameter before FSP $(0.47 \mu \mathrm{m})$.

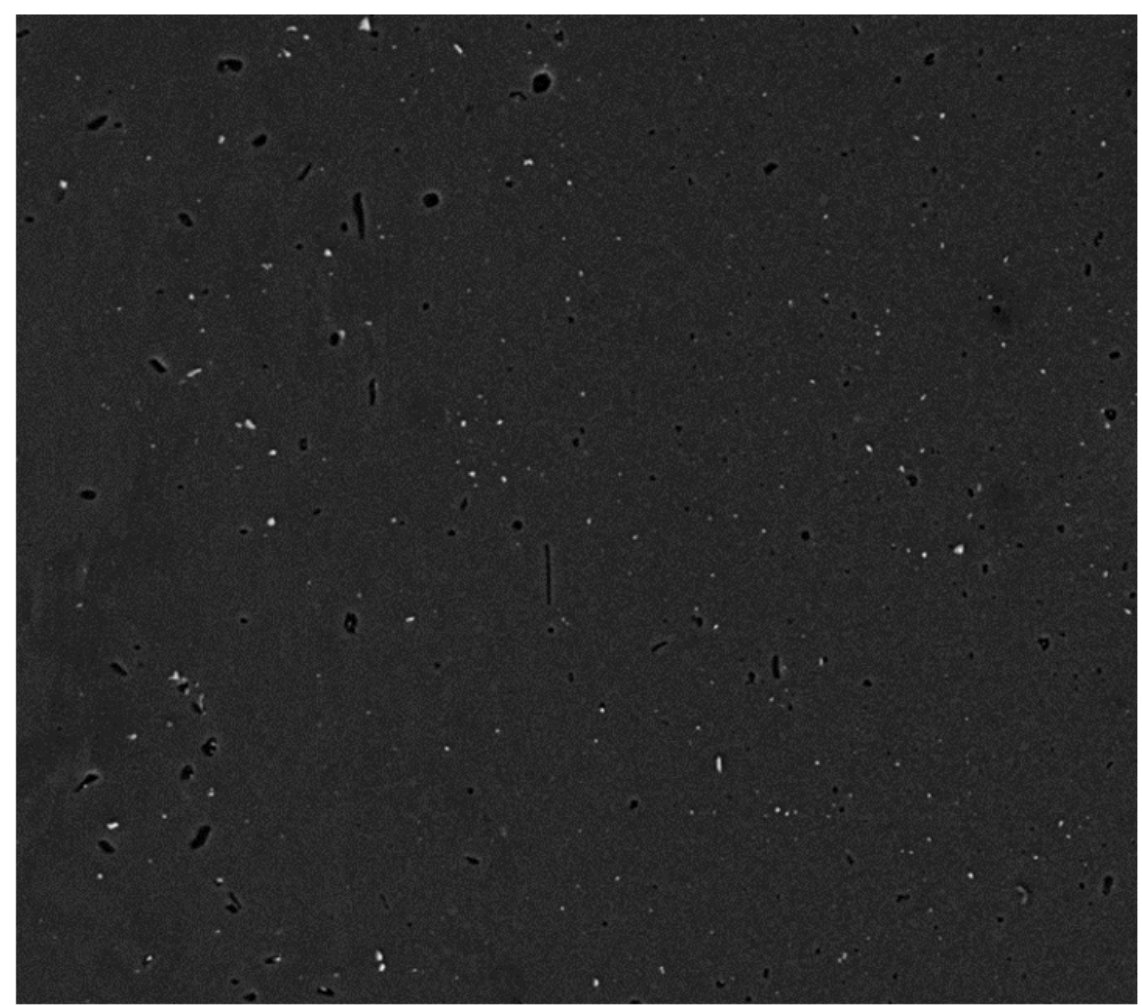

10um

Figure 5. SEM micrograph taken in BSE mode from the dynamically recrystallized zone (DXZ) in Figure 4, showing refined intermetallic particles (small bright particles).

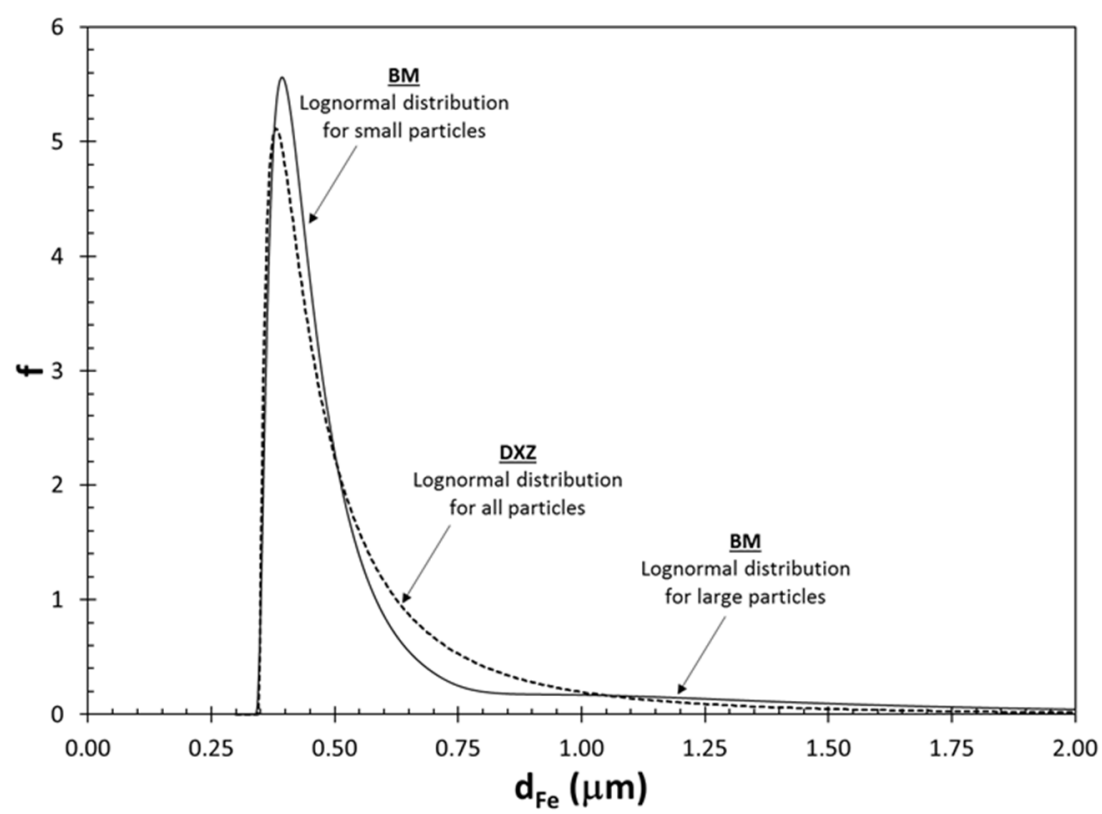

Figure 6. Fe particle size and distribution for the base material (No-FSP) and DXZ zone (FSP). 


\subsection{Characterization of Hardness Profile}

To evaluate the hardness profile developed during FSP in the material around the tool, Vickers microhardness tests were conducted starting adjacent to the tools and moving outward at regular intervals until the base metal was sampled. One of the twenty indentations created during the microhardness tests is presented in Figure 7.

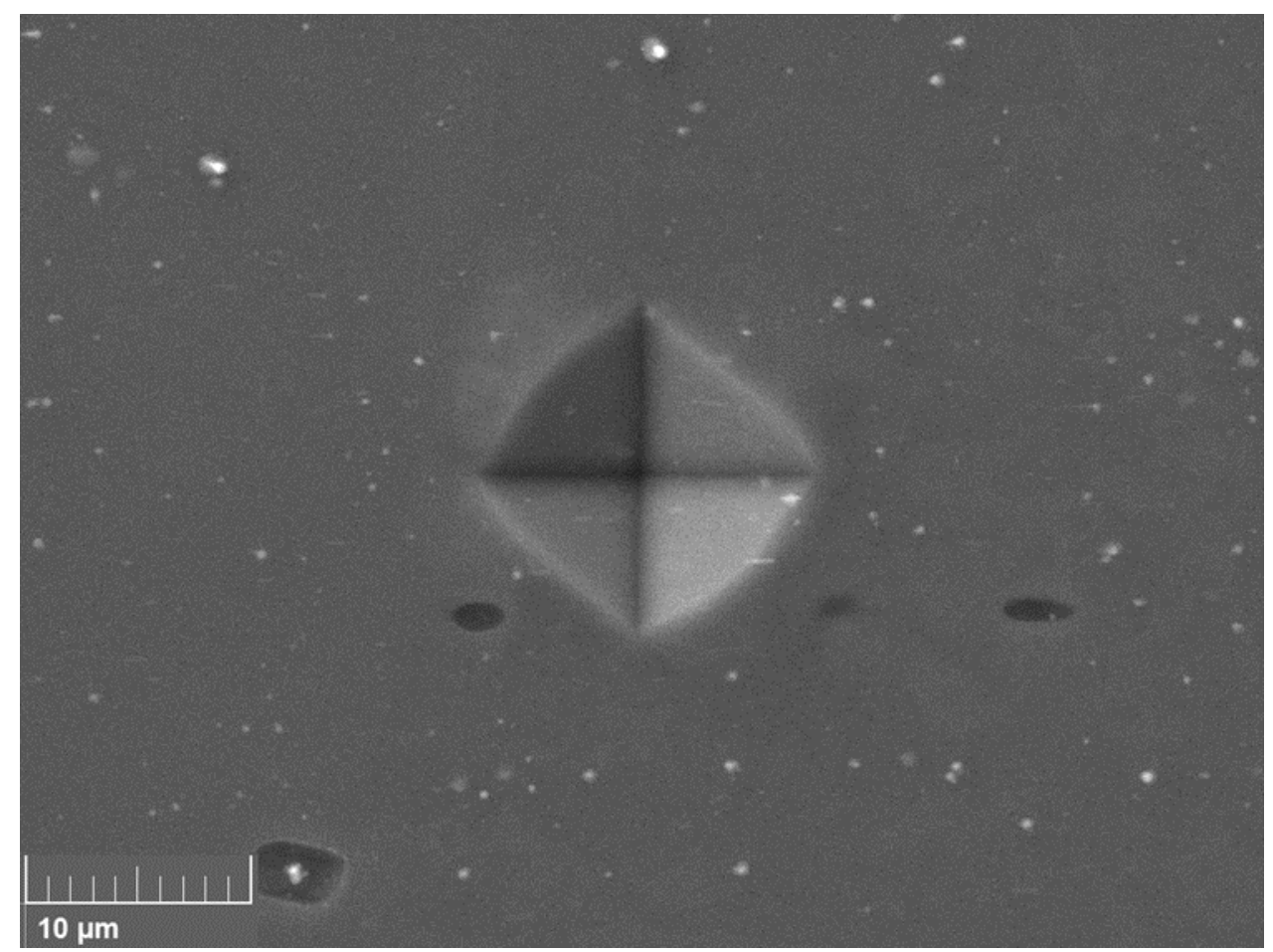

Figure 7. SEM micrograph taken in Secondary Electron (SE) mode of a Vickers microhardness test indentation in the DXZ region adjacent to the embedded tool.

The change in Vickers microhardness (Hv) with increasing distance from the FSP tool is presented in Figure 8, which shows the presence of four distinct zones, which have been interpreted to correlate with the regions suggested by Woo et al. [19]. It should be noted in the current analysis that the tool remains embedded in the sample, which is not the case in the Woo study; therefore, changes in the geometry of the regions and the extent of the DXZ must be considered. Further clarification of the variation between observed hardness in this study, and that presented by Woo et al. will be addressed later in the discussion. In the DXZ zone, the microstructure experiences greater plastic deformation than the other zones, and also results in more heat generation and lower hardness, likely the result of dissolution of strengthening precipitates in the $\mathrm{Al}$ matrix. Note that this zone extends from the tool surface to the boundary shown in Figure 4. In TMAZ, the reduction in material flow intensity resulted in a higher hardness profile than the DXZ. The HAZ was found to be the less affected zone by the stir action. An increase in the hardness from DXZ to the TMAZ is followed by an increase from TMAZ to the BM.

The difference between microhardness measured in the DXZ and BM in this study is $25 \mathrm{Hv}$, which is almost identical to the difference in these two zones from the Woo study, shown in Figure 1. Further comparison of the results of the two studies reveals that the widths of the zones in this study, as shown in Figure 8, are significantly smaller than those shown in Figure 1. The differences in the hardness profiles and the widths of the zones can be attributed to the differences in the process parameters in the two studies, and the presence of the remnant tool in the current investigation. Woo et al. conducted their experiments with an FSP tool that is of the same material used in the current study and with 
similar dimension, but using a transverse speed of $280 \mathrm{~mm} / \mathrm{min}$ and rotational speed of $1250 \mathrm{rpm}$, which are both significantly higher than the levels used in the current study $(50 \mathrm{~mm} / \mathrm{min}$ and $700 \mathrm{rpm})$. Additionally, Woo et al. applied a compressive pressure (12.4 MPa) under the tool, which was not applied in the current study.

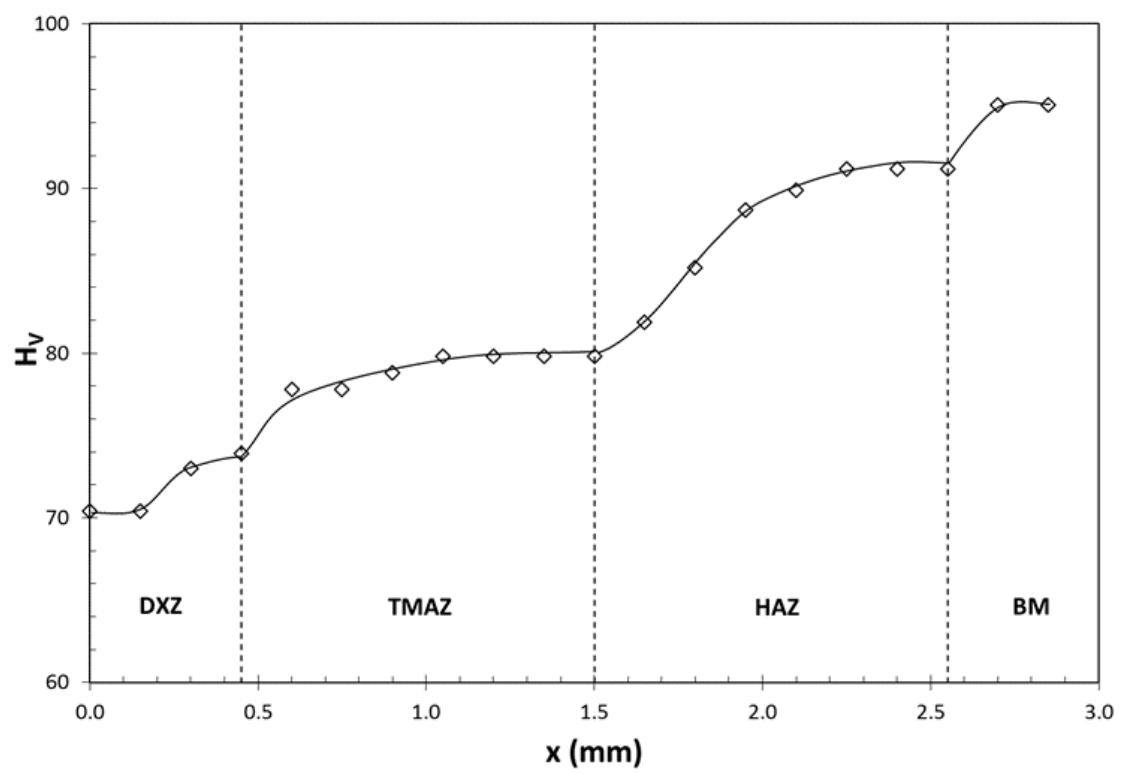

Figure 8. Microhardness profile of 6061-T6 extrusion as a function of distance from the tool edge.

\section{Conclusions}

- In the microstructure of 6061-T6 extrusions, there are two distinct size distributions for Fe-containing constituent particles: coarse particles in bands, and finer particles within the matrix. FSP was found to break up the large particles and refine them to the size of the initial finer particles within the matrix, which should improve mechanical properties.

- The hardness profile observed in this study was different from the one reported by Woo et al. for FSPed 6061-T6. In the microhardness profile away from the tool, four distinct zones, namely DXZ, TMAZ, HAZ, and BM, were visible. This difference was attributed to the differences in the process parameters used between the two studies, and the presence of the remnant tool in this study.

- The widths of the zones in the current study were also significantly smaller than those reported by Woo et al. These differences can also be attributed to the slower tool rotation and translation used in this study, which is presumed to result in a reduced length scale of the affected regions from the tool outward.

Data Availability: The raw/processed data required to reproduce these findings cannot be shared at this time as the data also form part of an ongoing study.

Author Contributions: The following contributions to this work were made by the following co-authorsConceptualization, M.T., N.N. and P.D.E.; Methodology M.T., N.N. and P.D.E.; Software, M.T., N.N.; Validation, M.T., N.N. and P.D.E.; Formal Analysis, N.N., M.T.; Investigation, N.N., P.D.E.; Resources, M.T. and P.D.E.; Data Curation, M.T. and N.N.; Writing-Original Draft Preparation, M.T., N.N., P.D.E.; Writing-Review and Editing, M.T., N.N. and P.D.E.; Visualization, N.N., P.D.E.; Supervision, M.T.; Project Administration, M.T.; Funding Acquisition, none.

Funding: This research received no external funding.

Acknowledgments: The images produced for this research were all taken in the Materials Science and Engineering Research Facility (MSERF) at UNF.

Conflicts of Interest: The authors declare no conflicts of interest. 


\section{References}

1. Mishra, R.S.; Mahoney, M.; McFadden, S.; Mara, N.; Mukherjee, A. High strain rate superplasticity in a friction stir processed $7075 \mathrm{Al}$ alloy. Scr. Mater. 1999, 42, 163-168. [CrossRef]

2. Mishra, R.S.; Mahoney, M.W. Friction stir processing: A new grain refinement technique to achieve high strain rate superplasticity in commercial alloys. Mater. Sci. Forum 2001, 357, 507-514. [CrossRef]

3. Mishra, R.S.; Ma, Z.Y. Friction stir welding and processing. Mater. Sci. Eng. R Rep. 2005, 50, 1-78. [CrossRef]

4. Jana, S.; Mishra, R.S.; Grant, G. Friction Stir Casting Modification for Enhanced Structural Efficiency: A Volume in the Friction Stir Welding and Processing Book Series; Butterworth-Heinemann: Oxford, UK, 2015.

5. Jana, S.; Mishra, R.S.; Baumann, J.A.; Grant, G.J. Effect of friction stir processing on microstructure and tensile properties of an investment cast Al-7Si-0.6Mg alloy. Metall. Mater. Trans. A 2010, 41, 2507-2521. [CrossRef]

6. Karthikeyan, L.; Senthilkumar, V.; Padmanabhan, K. On the role of process variables in the friction stir processing of cast aluminum A319 alloy. Mater. Des. 2010, 31, 761-771. [CrossRef]

7. Santella, M.L.; Engstrom, T.; Storjohann, D.; Pan, T.Y. Effects of friction stir processing on mechanical properties of the cast aluminum alloys A319 and A356. Scr. Mater. 2005, 53, 201-206. [CrossRef]

8. Ma, Z.Y.; Sharma, S.R.; Mishra, R.S. Effect of multiple-pass friction stir processing on microstructure and tensile properties of a cast aluminum-silicon alloy. Scr. Mater. 2006, 54, 1623-1626. [CrossRef]

9. Ma, Z.Y.; Sharma, S.R.; Mishra, R.S. Microstructural modification of as-cast Al-Si-Mg alloy by friction stir processing. Metall. Mater. Trans. A 2006, 37, 3323-3336. [CrossRef]

10. Jana, S.; Mishra, R.S.; Baumann, J.B.; Grant, G. Effect of friction stir processing on fatigue behavior of an investment cast Al-7Si-0.6 Mg alloy. Acta Mater. 2010, 58, 989-1003. [CrossRef]

11. Dewan, M.W.; Huggett, D.J.; Liao, T.W.; Wahab, M.A.; Okeil, A.M. Prediction of tensile strength of friction stir weld joints with adaptive neuro-fuzzy inference system (ANFIS) and neural network. Mater. Des. 2016, 92, 288-299. [CrossRef]

12. Chen, G.; Ma, Q.; Zhang, S.; Wu, J.; Zhang, G.; Shi, Q. Computational fluid dynamics simulation of friction stir welding: A comparative study on different frictional boundary conditions. J. Mater. Sci. Technol. 2018, 34, 128-134. [CrossRef]

13. Kumar, C.N.S.; Yadav, D.; Bauri, R.; Ram, G.D.J. Effects of ball milling and particle size on microstructure and properties $5083 \mathrm{Al}-\mathrm{Ni}$ composites fabricated by friction stir processing. Mater. Sci. Eng. A 2015, 645, 205-212. [CrossRef]

14. Netto, N.G.A. The Effect of Friction Stir Processing on the Microstructure and Tensile Behavior of Aluminum Alloys. Master's Thesis, University of North Florida, Jacksonville, FL, USA, 2018.

15. Kapoor, R.; Rao, V.S.H.; Mishra, R.S.; Baumann, J.A.; Grant, G. Probabilistic fatigue life prediction model for alloys with defects: Applied to A206. Acta Mater. 2011, 59, 3447-3462. [CrossRef]

16. Tiryakioglu, M.; Staley, J.T. Physical metallurgy and the effect of alloying additions in aluminum alloys. Handb. Alum. Phys. Metall. Process. 2003, 1, 81-209.

17. Zahedi, H.; Emamy, M.; Razaghian, A.; Mahta, M.; Campbell, J.; Tiryakioğlu, M. The Effect of Fe-rich intermetallics on the Weibull distribution of tensile properties in a cast Al-5 Pct Si-3 Pct Cu-1 Pct Fe-0.3 Pct Mg alloy. Metall. Mater. Trans. A 2007, 38, 659-670. [CrossRef]

18. DeBartolo, E.; Hillberry, B. A model of initial flaw sizes in aluminum alloys. Int. J. Fatigue 2001, 23, 79-86. [CrossRef]

19. Woo, W.; Choo, H.; Brown, D.W.; Feng, Z. Influence of the tool pin and shoulder on microstructure and natural aging kinetics in a friction-stir-processed 6061-T6 aluminum alloy. Metall. Mater. Trans. A 2007, 38, 69-76. [CrossRef]

20. Malopheyev, S.; Vysotskiy, I.; Kulitskiy, V.; Mironov, S.; Kaibyshev, R. Optimization of processing-microstructureproperties relationship in friction-stir welded 6061-T6 aluminum alloy. Mater. Sci. Eng. A 2016, 662, 136-143. [CrossRef]

21. Tiryakioğlu, M. Weibull analysis of mechanical data for castings II: Weibull mixtures and their interpretation. Metall. Mater. Trans. A 2015, 46, 270-280. [CrossRef]

(C) 2018 by the authors. Licensee MDPI, Basel, Switzerland. This article is an open access article distributed under the terms and conditions of the Creative Commons Attribution (CC BY) license (http:/ / creativecommons.org/licenses/by/4.0/). 